\title{
Crónica de una muerte anunciada: el ocaso del partido de Estado en Oaxaca
}

\author{
David Recondo
}

La movilización popular a partir del 14 de junio de 2006 en la ciudad de Oaxaca de Juárez y la victoria de la oposición en el estado en las elecciones federales del 2 de julio del mismo año están conectadas. Los dos procesos reflejan la crisis terminal de un régimen político sustentado en las tradicionales relaciones de dominación clientelista y autoritaria. Sin embargo, el vuelco electoral a favor de la oposición en las últimas elecciones presidenciales y legislativas no es una novedad absoluta. Al analizar en detalle la evolución de los resultados electorales en los 570 municipios de Oaxaca, aparece que tanto en el campo como en las ciudades el PRIl no ha dejado de perder votos desde finales de la década de 1980. La oposición (el PRD, el PAN y, más recientemente, el partido Convergencia) han ido ganando terreno de manera continua en los últimos veinte años. Oaxaca ha dejado, paulatinamente, de ser un bastión del voto "verde" para el PRI.

PALABRAS CLAVE: Oaxaca, elecciones federales, usos y costumbres, movimiento popular, conflicto político, democratización

The popular movement that emerged on June the 14th 2006 , in the city of Oaxaca de Juárez and the opposition's victory on the elections held on July the $2^{\text {nd }}$ of the same year are connected. Both processes reflect the terminal crisis of a political regime based on traditional clientele and authoritarian relationships as forms of domination. However, the electoral shift that favored the opposition during the last presidential and legislative elections isn't entirely new.After a detailed analysis of the evolution of the electoral results in the $\mathbf{5 7 0}$ districts of Oaxaca, one can conclude that the PRI (Institutional Revolutionary Party) has been loosing votes since the end of the eighties decade. The opposition (PRD, PAN, and recently the Convergencia) have gained ground during the last 20 years. Oaxaca has gradually ceased to be a stronghold of the PRI.

Keywords: Oaxaca, federal elections, traditional practices and customs, popular movement, political conflict, democratization

DAVID RECONDO: Centro de Estudios e Investigaciones Internacionales, Fundación Nacional de Ciencias Políticas (CERI-Sciences Po-CNRS), París, Francia recondo@ceri-sciences-po.org 
$\mathrm{L}$ as elecciones federales del 2 de julio en Oaxaca han tenido como telón de fondo uno de los conflictos más violentos desde 1977. En ese entonces, el gobernador Manuel Zárate Aquino renunció a su cargo tras una serie de enfrentamientos sangrientos entre la policía y manifestantes en Juchitán, San Juan Lalana y la ciudad de Oaxaca. El conflicto había empezado un año y medio antes, en el seno de la Universidad Autónoma Benito Juárez (UABJO), con demandas de democratización del funcionamiento interno de esa institución. Ante la cerrazón del gobernador electo en 1974, el movimiento se extendió a otros sectores de la capital y de las ciudades más importantes del estado, demandando mayor justicia social y democracia para todos. El presidente de la República, José López Portillo, pidió la renuncia del gobernador y nombró como interino al general Eliseo Jiménez Ruiz, quien pocos meses antes había acabado con la guerrilla de Lucio Cabañas en Guerrero. Eran tiempos en que el presidente, desde lo alto de la pirámide, ponía y quitaba gobernadores sin mayor protocolo (Martínez Vásquez, 1990 y 2007).

Treinta años después las cosas han cambiado mucho. Desde la alternancia del año 2000 el presidente de la República ya no es el "fiel de la balanza" y los gobernadores se han vuelto verdaderos jefes políticos, con sus propios recursos para mandar. Lo que no ha cambiado, sin embargo, es la pobreza que padece la mayoría de la población y el ejercicio autoritario del poder. Todo parece indicar que Oaxaca se ha convertido en un enclave autoritario, en un país cuyo régimen político se ha democratizado a nivel federal. Esto conforta la convicción de muchos observadores y analistas políticos que han considerado ese estado como una "reserva natural" de un voto "verde" para el Partido de la Revolución Institucional (PRI). No obstante, mostraremos en este artículo que la realidad actual de un poder estatal autocrático no va emparejada con la reproducción de un monopolio electoral; y que en Oaxaca, y en particular en las regiones con mayor presencia indígena, el voto se ha pluralizado constantemente, a la par del resto del país, hasta llegar a los resultados excepcionales del 2 de julio de 2006: un "carro completo", pero en beneficio de la opositora Coalición por el Bien de Todos, y no del PRI, como debió haber sido en un "bastión tradicional" del antiguo partido de Estado.

\section{EL MAGISTERIO, LA APPOY LAS ELECCIONES FEDERALES}

El conflicto arrancó con el tradicional plantón de los maestros de la sección 22 del Sindicato Nacional de Trabajadores de la Educación (SNTE). Desde 1980, cada 15 de mayo (día nacional del maestro) los mentores marchan para exigir un aumento salarial y el mejoramiento de las condiciones de trabajo. Lo normal era que los maestros acamparan en el centro histórico hasta que el gobernador cediera unos días antes de la celebración de la Guelaguetza (celebrada los dos primeros lunes de julio). En esta ocasión, el gobernador Ulises Ruiz Ortiz decidió romper con la tradición y mandó desalojar a los maestros en la madrugada del 14 de junio. El resultado fue un total fracaso ya que en pocas horas los maestros retomaron el control del centro de la ciudad. Además, la represión provocó un gran movimiento de solidaridad de parte de otros sectores de la sociedad civil. El 17 de junio un conjunto heterogéneo de organizaciones más o menos radicales —el Movimiento de Unificación y Lucha Triqui (MULT), el Comité de Defensa de los Derechos del Pueblo (CODEP), las Organizaciones Indias por los Derechos Humanos en Oaxaca (OIDHO), el Consejo Indígena Popular de Oaxaca "Ricardo Flores Magón” (CIPO-RFM), el Frente Popular Revolucionario (FPR), la Nueva Izquierda de Oaxaca (NIOAX) - y de organizaciones civiles y defensoras de los derechos humanos crea, junto con el magisterio, la Asamblea Popular de los Pueblos de Oaxaca (APPO). El movimiento logra congregar a muchos sectores populares de las zonas marginadas de la capital, así como un numero significativo - pero fluctuante- de vecinos del centro. La movilización se extiende con las bases rurales de las organizaciones citadas y rebasa totalmente a las policías municipal como estatal. No sólo los "appistas" instalan barricadas en toda la ciudad, sino que, además, toman el control del canal estatal de televisión (canal 9), de Radio Universidad y de varias radiodifusoras privadas. También desalojan y ocupan las oficinas gubernamentales y el congreso local, obligando al gobierno y a los diputados a despachar en casas particulares o en hoteles de Oaxaca y la ciudad de México. Los enfrentamientos violentos entre "rebeldes" y fuerzas policiacas 


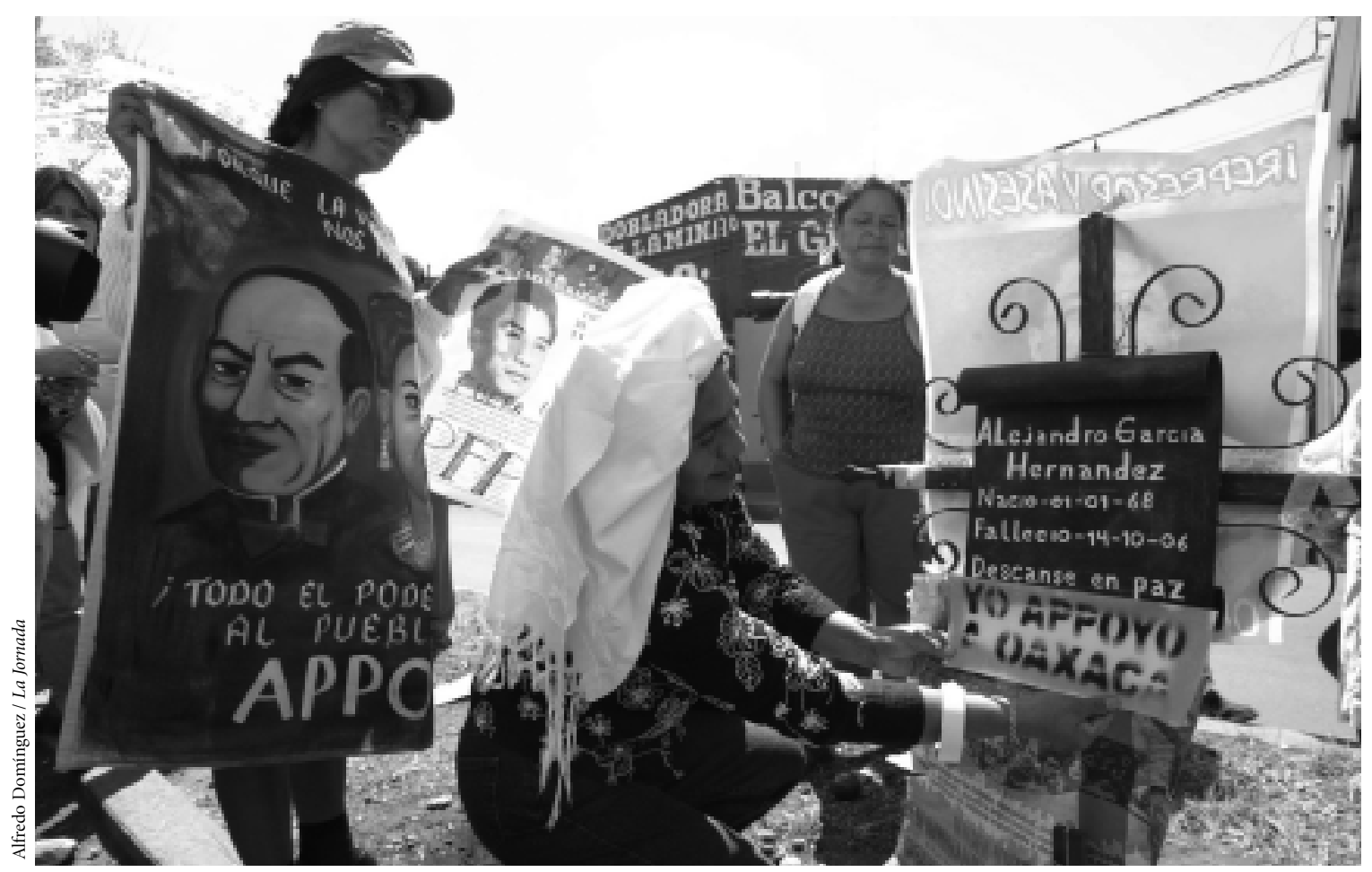

Mujeres rezando frente a la cruz de Alejandro García Hernandez, asesinado por apoyar el movimiento de la APPO, 13 de noviembre de 2006.

(incluyendo sicarios contratados por el gobernador para "limpiar" la ciudad) se multiplican durante meses, con su secuela de muertos, sin que el gobierno logre retomar el control de la ciudad. Mientras tanto, las negociaciones emprendidas con la mediación de la Secretaría de Gobernación no prosperan y el Senado se pronuncia en contra de la desaparición de poderes demandada por la APPO y el Partido de la Revolución Democrática (PRD) (Juan Martínez, 2007).

En una consulta organizada por la sección 22 del SNTE a mediados del mes de octubre la mayoría de los maestros decide regresar a clases a finales del mismo mes. El 27 de octubre, tras un enfrentamiento entre "appistas" y sicarios del gobernador (en el que muere un reportero estadounidense de Indymedia), el presidente Vicente Fox ordena la intervención de la Policía Federal Preventiva (PFP). Lo que sigue hasta el $1^{\circ}$ de diciembre es una serie de batallas campales entre los integrantes de la APPO, ubicados en las barricadas contra la PFP, reforzada con mili- tares disfrazados de policías. A partir de la entrada de la PFP en la ciudad los manifestantes se atrincheran en el campus de la Universidad Autónoma Benito Juárez de Oaxaca y mantienen una barricada en el crucero del periférico, junto a la Universidad. El último enfrentamiento masivo se da el domingo 25 de noviembre, cuando la APPO decide cercar a la PFP en el centro de la ciudad. El resultado es desastroso: varios edificios públicos son incendiados, entre ellos el Tribunal Superior de Justicia del Estado, la sede del Poder Judicial del Estado, las oficinas de la Secretaría de Turismo, las de la Secretaría de Relaciones Exteriores y las del Registro Público de la Propiedad. El enfrentamiento también deja un saldo de tres muertos y un centenar de heridos. Los días siguientes se desata una verdadera cacería de brujas, en la que caen más de un centenar de "appistas". La policía termina de "pacificar" la ciudad el 29 de noviembre, con el desmantelamiento de la última barricada. Los "brigadistas" de la APPO acaban entregando la radiodifusora de la Universidad — la 
última que controlaban-y abandonan el campus (Juan Martínez, 2006b). El último golpe a la APPO se produce el lunes 4 de diciembre en la ciudad de México, cuando cuatro de sus representantes son arrestados, incluyendo al dirigente de NIOAX, Flavio Sosa, una de las figuras más visibles del movimiento. Según declaraciones de la Comisión Nacional de Derechos Humanos (CNDH), el conflicto dejó un saldo de 20 muertos $^{1}$.

Las relaciones del conflicto con el proceso electoral federal son múltiples y ambiguas. Son muchos los actores políticos locales y nacionales que tienen vela en el entierro. No es casualidad si, por primera vez en 26 años, la huelga magisterial deriva en un conflicto de tal magnitud. La coyuntura electoral es propicia a la politización de un conflicto que en su inicio fue estrictamente gremial. La decisión de Ulises Ruiz Ortiz de enfrentarse con los maestros tiene mucho que ver con su falta de habilidad política. Excelso en el arte de la "alquimia" electoral, se ha revelado un pésimo operador político. Desde el inicio de su mandato ha cortado todos los vínculos que su antecesor, José Murat Casab, había tejido, en clave clientelista, con todas las fuerzas políticas del estado. Confrontado a un proceso electoral muy competido (gana con sólo $3 \%$ de ventaja sobre su más cercano contendiente, Gabino Cué Monteagudo, que encabezó una coalición del PRD, Partido Acción Nacional [PAN] y Convergencia²) y una movilización poselectoral sin precedente, el gobernador ha optado por la intransigencia en lugar de tratar de cooptar parte de la oposición. Pero el estilo personal no es una explicación suficiente. Ulises Ruiz tuvo un margen de acción limitado porque su padrino, Roberto Madrazo, le asignó una misión específica: financiar su campaña

${ }^{1}$ Informe especial sobre los hechos sucedidos en la ciudad de Oaxaca el 2 de junio de 2006 al 31 de enero de 2007, CNDH, México, 15 de marzo de 2007.

2 Partido Convergencia por la Democracia, al cual pertenece Gabino Cué Monteagudo, ex presidente municipal de Oaxaca de Juárez (20012004) y senador por el estado de Oaxaca (2006-2012). Este partido fue creado a nivel nacional, en 1999, por ex prí́stas encabezados por Dante Delgado Rannauro, ex gobernador de Veracruz (1988-1992). En Oaxaca, el ex gobernador sustituto de Oaxaca, Jesús Martínez Álvarez (19851986), dueño del diario estatal Noticias y diputado federal (2003-2006) es uno de los principales líderes de Convergencia junto con Alberto Esteva Salinas, su actual presidente estatal y diputado federal plurinominal (2006-2012). Jesús Martínez Álvarez renunció al PRI en 2001, tras presidencial. También se comprometió en aportarle un millón de votos, pero el principal objetivo siempre fue canalizar recursos hacia la campaña electoral. En ese sentido, el gobernador de Oaxaca cumplió su misión con un desvío evaluado en varios millones de pesos. Evidentemente, el dinero que fue a las arcas de Madrazo ya no pudo ser utilizado para comprar lealtades políticas. Los maestros y varios de los grupos radicales que se movilizan contra Ulises Ruiz lo hacen simplemente porque éste ha dejado de cumplir con los compromisos que había establecido José Murat. El equilibrio sutil entre cooptación, intimidación y represión que éste ejerció con sobrada habilidad se resquebrajó. El palo reemplazó definitivamente a la zanahoria (Juan Martínez, 2006a).

Mucho se ha especulado sobre la decisión de desalojar a los maestros: ¿simple error táctico de parte de un gobernador "novato" y poco hábil en el arte de gobernar las multitudes o, al contrario, movida deliberada para poner en dificultad a la oposición y, en particular, el Partido Nueva Alianza (Panal) recién creado por Elba Esther Gordillo, secretaria general del SNTE y acérrima enemiga de Roberto Madrazo? El objetivo puede haber sido, efectivamente, orillar a los maestros a radicalizar su movimiento para acusar a la "maestra" de fomentar la violencia y el caos. También el gobernador pudo haber querido poner a Vicente Fox y al PAN ante el dilema de intervenir y mancharse las manos de sangre o no hacer nada y aparecer, así, como incapaces de asegurar la gobernabilidad del país. De hecho, Ulises Ruiz acusó al gobierno federal de haber provocado el conflicto al no transferirle a su gobierno los recursos suficientes para responder a las demandas del magisterio. Pero, en todo caso, el resultado fue totalmente inverso, aunque la dirigencia magisterial no llamó a votar por un partido ni por un candidato presidencial, en particular, sí llamó a sancionar al partido del gobernador. En vísperas del 2 de julio, los maestros regresaron a sus domicilios y/o lugares de trabajo para votar y llamar

su ruptura con el entonces gobernador José Murat Casab (1998-2004). Gabino Cué Monteagudo se afilió a Convergencia en 2001, tras haber sido colaborador cercano del ex gobernador de Oaxaca (1992-1998) y ex secretario de Gobernación (1999-2000), Diódoro Carrasco Altamirano; desde septiembre de 2006 ocupa el curul de senador por Oaxaca. 
a la población a sancionar al PRI en las urnas. El resultado fue contundente: el candidato de la Coalición por el Bien de Todos, Andrés Manuel López Obrador, que poco había hecho para apoyar la "rebelión" magisterial y popular, ganó las elecciones en Oaxaca y la coalición opositora (PRD-Partido del Trabajo, PT-Convergencia) se llevó nueve de las once diputaciones de mayoría relativa y dos de las tres senadurías, incluyendo al ex candidato a gobernador Gabino Cué Monteagudo.

Haremos un análisis más detallado de los resultados electorales del 2 de julio en la próxima sección, pero es importante por ahora mostrar cómo la represión del 14 de junio y el movimiento social que contribuyó a reforzar, así como la reacción del gobierno federal al respaldar a Ulises Ruiz Ortiz, provocaron que la participación electoral fuera más elevada que nunca y que el voto favoreciera a los candidatos de oposición al PRI y al PAN. Es posible que ese resultado sea coyuntural y que en las siguientes elecciones (municipales y estatales en agosto y octubre de 2007, legislativas federales en 2009, gobernatura en 2010 y presidencial en 2012) el PRI se pueda restablecer o el voto opositor estatal pueda beneficiar a otro partido que el PRD y sus aliados (Convergencia y PT). Aún así, los resultados del 2 de julio de 2006 no son una sorpresa. El PRI no ha dejado de perder votos desde finales de la década de 1980. En todos esos años, el PRD (y a partir de 2001, Convergencia) se ha beneficiado de ese desgaste en la mayor parte del estado. El PAN también ha obtenido resultados significativos a partir de la década de 1990 en las grandes ciudades (ciudad de Oaxaca, Tuxtepec, Huajuapan, Matías Romero), pero también en las regiones rurales a partir de 2000 (en la región con mayor población indígena - la Sierra Norte, por ejemplo-, Vicente Fox obtuvó la segunda posición después de Francisco Labastida, del PRI). Así pues, mirando de cerca los resultados electorales de los últimos 14 años (estatales y federales) la representación de Oaxaca como bastión del PRI deja de ser pertinente. De hecho, aparece que la pluralización del voto y la erosión del capital electoral príista se da de la misma manera en los municipios potencialmente más indígenas y tradicionalistas que en 1995 han adoptado el régimen de "usos y costumbres" introducido en el código electoral del estado.

\section{CUANDO LA COSTUMBRE DEJA DE FAVORECER AL PRI: LA PLURALIZACIÓN DEL VOTO INDÍGENA}

Desde el 30 de agosto de 1995 Oaxaca tiene una legislación electoral especial que reconoce como válidos los procedimientos llamados de "usos y costumbres". Para reglamentar la reforma constitucional de sesgo multiculturalista impulsada en 1990 por el gobernador de ascendencia mixteca, Heladio Ramírez López (1986-1992), el Congreso de Oaxaca aprobó la creación de un libro adicional en el código electoral que reconoce a las comunidades del estado el derecho de nombrar a sus autoridades municipales en asambleas públicas, sin la intervención $d i$ recta de los partidos políticos y fuera de la fecha oficial de las elecciones, como se venía haciendo desde la época novohispana (Flores Cruz, 2005; Recondo, 2001a; Velásquez Cepeda, 2000: 134-147). Se crea así una distinción entre dos tipos de municipios: aquellos donde la renovación de los ayuntamientos se hace según la costumbre — 418 municipios en total- y aquellos donde los partidos políticos registran candidatos antes del día oficial de las elecciones - los 152 municipios restantes del estado- - Desde el inicio, los requisitos para determinar el régimen de cada municipio son vagos; la nueva reglamentación sólo precisa que "se entiende por comunidades de un municipio que observa el régimen de usos y costumbres aquellas que desde tiempo inmemorial o, cuando menos desde hace tres años, eligen a sus autoridades mediante mecanismos establecidos por su derecho consuetudinario" (IEE, 1995: 28). El nuevo código electoral establece que "las comunidades [...] registrarán a sus candidatos directamente, sin la intervención de partido alguno, o bien a través de alguno de éstos" (ibid.). Una segunda reforma de septiembre de 1997 le da mayor precisión a los mecanismos de definición del régimen electoral de los 570 municipios del estado — no sin dejar vacíos que siguen suscitando numerosas controversias hasta la fecha- Pero sobre todo, determina claramente que "los ayuntamientos electos bajo normas de derecho consuetudinario no tendrán filiación partidista" (IEE, 1998: 79). Esta norma atípica en un régimen republicano provoca que coexistan, en un mismo territorio, dos mane- 
ras de concebir la ciudadanía —en particular el derecho de votar y ser votado-y las formas de participación y representación política a nivel local. Lo que algunos autores han llamado "ciudadanía étnica" (De la Peña, 1994) o "ciudadanía multicultural” (Kymlicka, 1995), es una realidad en el sur de México. Es interesante ver el impacto que ha tenido ese reconocimiento de los usos y costumbres a nivel local en los procesos electorales supra-municipales. En la polémica que acompañó la reforma y que resurge en cada elección, tanto políticos como académicos han denunciado una estrategia del PRI para preservar el monopolio en las regiones "tradicionalistas" donde las costumbres han sido "infiltradas" por el otrora partido "oficial". El intelectual Roger Bartra, por ejemplo, ha denunciado la legitimación de lo que considera "formas de gobierno integristas, sexistas, discriminatorias, religiosas y corporativas" que, lejos de expresar una democracia directa cualquiera, forman parte de un "viejo modelo autoritario" (Bartra, 1999: 27-40). Su diagnóstico, fundado en la comparación de datos etnográficos provenientes de toda la República mexicana, es categórico:

Los sistemas normativos indígenas - o lo que queda de ellos- son formas coloniales político-religiosas de ejercicio de la autoridad [...], profundamente infiltradas y hábilmente manipuladas por los intereses de mestizos o ladinos y por la burocracia política de los gobiernos posrevolucionarios con el fin de estabilizar la hegemonía del Estado nacional en las comunidades indígenas (Bartra, 1999: 34-35).

Otorgarles reconocimiento legal equivale a crear un régimen de apartheid (Bartra, 1999: 187). Lejos de contribuir a la democratización del régimen, se corre el riesgo de engendrar más conflictos y violencia.

Otros estudiosos son más mesurados, pero consideran que la existencia de una normatividad "usocostumbrista” a nivel municipal crea mayores conflictos en el desarrollo de las elecciones federales, desde su preparación (selección y capacitación de los funcionarios de casilla, votación, cómputo, etc.). Así, José Antonio Aguilar y Guillermo Trejo hablan de la "esquizofrenia" que provoca la coexistencia de sistemas normativos diferenciados en una misma circunscripción electoral, lo que desemboca en mayores niveles de rechazo hacia los partidos, las autori- dades electorales y mayores niveles de abstención (Aguilar y Trejo, 2002: 195-200). Para otros, el PRI ha logrado mantener su hegemonía electoral gracias al reconocimiento de los usos y costumbres, simbióticamente ligados al partido "oficial” (Anaya, 2002).

Sin embargo, el análisis pormenorizado y diacrónico de los resultados electorales nos da una visión bastante diferente (Díaz Montes y Martínez Vásquez, 2001; Díaz Montes, 2004; Martínez Vásquez, 2004). En las siguientes secciones comparamos los resultados de elecciones estatales y federales de 1992 a 2006 en los municipios de usos y costumbres y en los de partidos políticos ${ }^{3}$. Hasta las últimas elecciones veremos cómo la votación es ligeramente más favorable al PRI en el primer tipo de municipios, mientras que la oposición ha crecido, incluso de manera más marcada, que en el segundo tipo de municipios.

\section{La elección de gobernador: la evolución de 1992 a 2004}

Si comparamos los resultados en las tres últimas elecciones de gobernador (1992, 1998 y 2004) en el conjunto de los municipios de Oaxaca, el PRI pasó de 79\% de los sufragios a 49\%: los votos del partido "oficial" se redujeron en 30\% (véase cuadro 1). Lo interesante es que la disminución más fuerte se produjo en los 418 municipios de usos y costumbres, donde los votos ganados por el PRI (en alianza con el PT y el PVEM) en 2004 representan $52.72 \%$ de los sufragios, contra $87 \%$ en 1992: es decir, el PRI perdió 34 puntos en 12 años, mientras que en los 152 municipios de partidos políticos sus votos se redujeron 25 puntos, al pasar de 73 a 48\%. Además, en 2004 la coalición dirigida por el PRI recuperó 3\% de los votos válidos en los municipios de partidos políticos en comparación

\footnotetext{
${ }^{3}$ Los cálculos se realizaron con base en los datos oficiales de las elecciones desglosados a nivel municipal proporcionados por el Instituto Estatal Electoral y el Instituto Federal Electoral. Para comparar el comportamiento electoral en las dos categorías de municipios (de régimen partidista y de usos y costumbres) usamos una tabla Excell, en la que vaciamos la lista de los 570 municipios indicando su régimen electoral. Así pudimos hacer la suma de los resultados en los 570 municipios, y luego, por separado (usando un filtro), en los 418 municipios de usos y costumbres y en los 152 municipios de partidos políticos.
} 
Cuadro 1. Elección de gobernador en los 570 municipios de Oaxaca

\begin{tabular}{l|c|c|c}
\hline & 1992 & 1998 & 2004 \\
\hline PRI & $79 \%$ & $49 \%$ & $(\mathrm{NFO})^{4} 49 \%$ \\
\hline PRD & $10 \%$ & $38 \%$ & $(\mathrm{TSO})^{5} 46 \%$ \\
\hline PAN & $5 \%$ & $10 \%$ & \\
\hline Otros $^{6}$ & $6 \%$ & $3 \%$ & $5 \%$ \\
\hline
\end{tabular}

FUENTE: Elaborado por el autor con datos del IEE.

con las elecciones de 1998, en las cuales sólo avanzó 1\% en los municipios de usos y costumbres (véanse cuadros 2 у 3$)$.

Si examinamos los resultados de la oposición, la evolución es todavía más significativa. En el conjunto de 570 municipios de Oaxaca (sin distinción de categoría electoral), la oposición pasa de $21 \%$ de los sufragios en 1992 a 50\% en 2004 (con un pico de 51\% en 1998). El PRD da un formidable salto en 1998, pasando de 10 a 38\% de los sufragios. Si comparamos los resultados de la oposi-

${ }^{4}$ Nueva Fuerza Oaxaqueña, alianza PRI-PT-PVEM que postuló la candidatura de Ulises Ruiz Ortiz a gobernador en las elecciones estatales del 2 de agosto de 2004.

5 Todos Somos Oaxaca, coalición PAN-PRD-Convergencia que postuló a Gabino Cué Monteagudo (Convergencia) a gobernador en las elecciones del 2 de agosto de 2004. En esa coyuntura el partido Convergencia se constituyó en el eje articulador de la oposición ante un PRD debilitado por sus conflictos internos y, en particular, por las divisiones entre facciones de la COCEI (Coalición Obrera Estudiantil del Istmo), cuyos dirigentes se repartieron entre el PRD (Alberto Reyna - presidente municipal de Juchitán desde 2004—, Roberto López Rosado, Leopoldo de Gyves, Óscar Cruz López, Lenin López Nelio, entre otros), el PT (Mario Santana) y el Partido Unidad Popular, creado en noviembre de 2003 (Héctor Sánchez López, fundador de la COCEI, ex presidente municipal de Juchitán —1989-1992 —, senador —1994-2000 —, diputado federal —2000-2003 - y candidato a gobernador por el PRD en 1998 y por el PUP en 2004; ingresó al Partido Alternativa Socialdemócrata y Campesina - PASC - en 2005, del cual salió a los pocos meses al no lograr impulsar la candidatura de Víctor González Torres —el Doctor Simi- en contra de Patricia Mercado. Desde diciembre de 2006, Héctor Sánchez es secretario técnico de la Comisión Estatal para la Reforma del Estado de Oaxaca, creada por iniciativa del gobernador Ulises Ruiz Ortiz en diciembre de 2006).

${ }^{6}$ Candidatos no registrados y candidato del Partido Unidad Popular, creado a finales de 2003 y liderado por el dirigente del Movimiento de Unificación y Lucha Triqui (MULT), Heriberto Pazos. En 2004, el candidato a la gobernatura por este partido fue el ex perredista Héctor Sánchez López.
Cuadro 2. Elección de gobernador en los municipios de partidos políticos

\begin{tabular}{l|c|c|c}
\hline & 1992 & 1998 & 2004 \\
\hline PRI & $73 \%$ & $45 \%$ & (NFO) $48 \%$ \\
\hline PRD & $13 \%$ & $36 \%$ & (TSO) $49 \%$ \\
\hline PAN & $7 \%$ & $12 \%$ & \\
\hline Otros & $7 \%$ & $7 \%$ & $3 \%$ \\
\hline
\end{tabular}

FUENTE: Elaborado por el autor con datos del IEE.

Cuadro 3. Elección de gobernador en los municipios de usos y costumbres

\begin{tabular}{l|c|c|c}
\hline & 1992 & 1998 & 2004 \\
\hline PRI & $87 \%$ & $52 \%$ & (NFO) $53 \%$ \\
\hline PRD & $5 \%$ & $36 \%$ & (TSO) $40 \%$ \\
\hline PAN & $4 \%$ & $5 \%$ & \\
\hline Otros & $4 \%$ & $7 \%$ & $7 \%$ \\
\hline
\end{tabular}

FUENTE: Elaborado por el autor con datos del IEE.

ción en los municipios tanto de usos y costumbres como de partidos, vemos que su progreso fue mayor en la primera categoría que en la segunda: en los municipios de usos y costumbres la oposición pasa de 13\% de los sufragios en 1992 a 47\% en 2004, mientras que en los municipios de partidos políticos pasa de $27 \%$ de los sufragios en 1992 a 52\% en 2004. En otras palabras, mientras que en los municipios de partidos políticos la oposición apenas duplica sus resultados, casi los cuadruplica en los municipios de usos y costumbres.

Pero los resultados del PRD son todavía más significativos: en los municipios de partidos políticos pasa de 13\% de los sufragios en 1992 a 36\% en 1998, mientras que en los de usos y costumbres pasa de 5 a 36\% (la comparación no es posible con los resultados de 2004, ya que el PRD, junto con el PAN y Convergencia por la Democracia, postularon al mismo candidato, Gabino Cué Monteagudo). En otras palabras, los resultados del PRD aumentan dos veces más en los municipios de usos y costumbres que en el resto de los municipios. Esto contradice la imagen de la "barrera" consuetudinaria que supuestamente 
Cuadro 4. Elección de presidente de la República en los $\mathbf{5 7 0}$ municipios de Oaxaca

\begin{tabular}{l|c|c|c}
\hline & 1994 & 2000 & 2006 \\
\hline PRI & $52 \%$ & $44 \%$ & $33 \%$ \\
\hline PRD & $28 \%$ & $26 \%$ & $47 \%$ \\
\hline PAN & $13 \%$ & $27 \%$ & $17 \%$ \\
\hline Otros & $7 \%$ & $3 \%$ & $3 \%$ \\
\hline
\end{tabular}

FUENTE: Elaborado por el autor con datos del IEE y del IFE.

sirve para contener los progresos de la oposición. La evolución de los resultados electorales se explica, en gran medida, por una diferencia en el punto de partida: a principios de la década de 1990 el PRI obtenía más de 85\% de los votos en los municipios de usos y costumbres, mientras que se situaba ya alrededor de $70 \%$ en el resto de los municipios. Es como si la oposición hubiera recuperado, entre 1992 y 2004, un retraso acumulado hasta ese momento en las zonas rurales e indígenas.

Los datos para 2004 muestran también que por primera vez en la historia posrevolucionaria de Oaxaca, la oposición obtuvo más votos que la alianza dominada por el PRI (51\% contra 49\%). El Partido de Unidad Popular (PUP), cuyo candidato a gobernador es Héctor Sánchez López, ha sido creado por Heriberto Pazos, dirigente fundador del MULT, que en 1998 había apoyado la campaña de Héctor Sánchez, entonces candidato por ¡el PRD! La creación del PUP, un partido cuyos estatutos hacen hincapié en su base indígena, ha sido muy polémica. En un primer momento el IEE rechazó la acreditación de este nuevo partido con argumentos de técnica jurídica poco convincentes, pero sus dirigentes apelaron ante el Tribunal Estatal Electoral que, tras semanas de vacilaciones, acabó dándoles la razón. Este cambio de decisión en dos instancias controladas por el gobernador José Murat Casab ha sido interpretado como el resultado de un nuevo cálculo táctico. Al constituirse la coalición PAN-PRD-Convergencia, José Murat decidió avalar el PUP para restarle votos a la oposición, a la vieja usanza príísta. El resultado fue concluyente, ya que el PUP se llevó el 4\% que le faltó a la Coalición Todos Somos Oaxaca para ganarle a Ulises Ruiz Ortiz. No es casualidad que a fines de 2006
Cuadro 5. Elección de presidente de la República en los municipios de partidos políticos

\begin{tabular}{l|c|c|c}
\hline & 1994 & 2000 & 2006 \\
\hline PRI & $51 \%$ & $41 \%$ & $30 \%$ \\
\hline PRD & $29 \%$ & $26 \%$ & $47 \%$ \\
\hline PAN & $15 \%$ & $31 \%$ & $20 \%$ \\
\hline Otros & $5 \%$ & $2 \%$ & $3 \%$ \\
\hline
\end{tabular}

FUENTE: Elaborado por el autor con datos del IEE y del IFE.

el gobernador electo le haya confiado a Héctor Sánchez el cargo de secretario técnico de la controvertida Comisión Especial para la Reforma del Estado.

\section{Las elecciones presidenciales de 1994 a 2006}

El análisis de los resultados en las elecciones presidenciales de 1994, 2000 y 2006 confirma que el voto se ha pluralizado de la misma manera en los municipios de usos y costumbres y en los de partidos políticos. Si bien el PRI saca mejores resultados en la primera categoría de municipios que en la segunda (4\% más en 1994 y en 2006; $11 \%$ más en 2000), en los dos casos pierde 21 puntos entre 1994 y 2006 (véanse cuadros 5 y 6).

Lo más significativo es la evolución del conjunto de la oposición. Entre 1994 y 2000, ésta progresa mucho menos en los municipios de usos y costumbres en comparación con los de partidos políticos (3\% contra 10\%), pero se da un verdadero vuelco en las presidenciales de 2006, donde por primera vez la oposición gana las elecciones, de 2 a 1 en los 570 municipios. En los municipios de usos y costumbres, la oposición obtiene 18\% más que en 2000, cuando en los municipios de partidos políticos avanza 11\%, sólo 1\% más que entre 1994 y 2000. La oposición sigue ganando mejor en la segunda categoría de municipios que en la primera $(70 \%$ contra $66 \%)$, pero la diferencia es mínima (4\%). Finalmente, la evolución entre los dos tipos de municipios es la misma.

Cabe resaltar que la influencia política del magisterio no favoreció al nuevo partido Panal (Partido Nueva Alianza), creado por Elba Esther Gordillo y dirigido por cua- 
Cuadro 6. Elección de presidente de la República en los municipios de usos y costumbres

\begin{tabular}{l|c|c|c}
\hline & 1994 & 2000 & 2006 \\
\hline PRI & $55 \%$ & $52 \%$ & $34 \%$ \\
\hline PRD & $28 \%$ & $25 \%$ & $48 \%$ \\
\hline PAN & $10 \%$ & $19 \%$ & $16 \%$ \\
\hline Otros & $7 \%$ & $4 \%$ & $2 \%$ \\
\hline
\end{tabular}

FUENTE: Elaborado por el autor con datos del IEE y del IFE.

dros del Sindicato Nacional de Trabajadores de la Educación (SNTE). El candidato de este partido a la presidencia, el ex priísta Roberto Campa Cifrián, sólo obtiene 0.43\% de los votos válidos en los 570 municipios, con una diferencia mínima en los dos tipos de municipios $(0.44 \%$ en los de usos y costumbres y $0.41 \%$ en los de partidos políticos). Hasta el Partido Socialdemócrata y Campesino, de reciente creación y con Patricia Mercado como candidata, obtiene un mejor resultado $(1.49 \%$ en los 570 municipios; $1.32 \%$ en los de usos y costumbres; $1.72 \%$ en los de partidos políticos). Los malos resultados del Panal se explican porque Elba Esther Gordillo ha sido acusada por los maestros de la sección 22 de perpetuar el "charrismo" contra el cual se habían rebelado en 1980, cuando Carlos Jonguitud Barrios controlaba el sindicato con mano de hierro. De hecho, la secretaria general del SNTE jamás le ha dado reconocimiento formal a la sección $22 \mathrm{y}$, tras las últimas elecciones presidenciales y el conflicto de Oaxaca, ha impulsado la creación de una sección 59, con maestros disidentes.

El dato clave es la victoria de Andrés Manuel López Obrador, el candidato de la Coalición por el Bien de Todos, el 2 de julio de 2006, tanto en los municipios de usos y costumbres como en los de partidos políticos $(47.52 \%$ en los primeros y $47.31 \%$ en los segundos, contra $34.51 \%$ y $30.33 \%$ para Roberto Madrazo, candidato de la Alianza por México, respectivamente). Es la primera vez, desde la fundación del PRI, que éste no gana una elección federal en Oaxaca. Este sorprendente resultado se refleja también en los resultados de la elección para diputados federales y senadores.
Cuadro 7. Elección de diputados federales en los $\mathbf{5 7 0}$ municipios de Oaxaca

\begin{tabular}{l|c|c|c|c|c}
\hline & 1994 & 1997 & 2000 & 2003 & 2006 \\
\hline PRI & $53 \%$ & $50 \%$ & $45 \%$ & $52 \%$ & $35 \%$ \\
\hline PRD & $27 \%$ & $31 \%$ & $26 \%$ & $21 \%$ & $43 \%$ \\
\hline PAN & $13 \%$ & $13 \%$ & $26 \%$ & $22 \%$ & $17 \%$ \\
\hline Otros & $7 \%$ & $6 \%$ & $4 \%$ & $6 \%$ & $4 \%$ \\
\hline
\end{tabular}

FUENTE: Elaborado por el autor con datos del IEE y del IFE.

\section{Las elecciones legislativas federales de 1994 a 2006: un retroceso constante del PRI}

Las elecciones de diputados federales de 1994 a 2006 confirman las tendencias observadas en las elecciones de gobernador y en las de presidente de la República. El PRI sigue perdiendo votos en el conjunto de los municipios. Pasa de 53\% de los sufragios en 1994 a 35\% en 2006, una disminución de 18\%. La oposición, por su parte, pasa de 47\% de los sufragios en 1994 a 64\% en 2006 (véase cuadro 7). El retroceso del PRI es ligeramente más pronunciado en los municipios de usos y costumbres (20\%) que en los de partidos políticos (19\%).

Las elecciones de 2003 aparecen como una excepción: el PRI recupera prácticamente la proporción de votos válidos que obtuvo en 1994 (52\% contra 53\%), después de haber obtenido el resultado más bajo en 2000 (45\%). Sin embargo, entre las elecciones generales de $2000 \mathrm{y}$ 2006, el PRI ha perdido 10\% de los votos válidos. Las legislativas de 2003 aparecen, pues, como un paréntesis en un proceso lento y constante de retroceso para el antiguo partido de Estado.

Estos datos muestran claramente que los municipios de usos y costumbres no son ajenos al cambio que condujo a la alternancia presidencial en 2000, ya que el PAN duplicó sus resultados al pasar de $8 \%$ a $18 \%$ de los sufragios entre 1997 y 2000. El 2 de julio de 2006, el PRI deja de ser mayoritario, tanto en la elección de diputados como en la de presidente ( $37 \%$ contra $63 \%$ para el conjunto de la oposición); el voto se pluraliza de igual manera en estos municipios y en el resto. El PRD sigue siendo la segunda fuerza política, con 43\% de los sufragios en 2006, 
Cuadro 8 Elección de diputados federales en los municipios de partidos políticos

\begin{tabular}{l|c|c|c|c|c}
\hline & 1994 & 1997 & 2000 & 2003 & 2006 \\
\hline PRI & $52 \%$ & $47 \%$ & $42 \%$ & $49 \%$ & $33 \%$ \\
\hline PRD & $28 \%$ & $32 \%$ & $26 \%$ & $19 \%$ & $43 \%$ \\
\hline PAN & $14 \%$ & $15 \%$ & $29 \%$ & $23 \%$ & $19 \%$ \\
\hline Otros & $7 \%$ & $6 \%$ & $3 \%$ & $9 \%$ & $4 \%$ \\
\hline
\end{tabular}

FUENTE: Elaborado por el autor con datos del IEE y del IFE.

después de haberse ubicado en tercera posición detrás del PAN en 2003 (20\% contra 22\%). Es en la variación de los votos del PAN que aparece la diferencia más fuerte entre los municipios de usos y costumbres y los de partidos políticos. En estos últimos, el PAN rebasa al PRD por tres puntos porcentuales en 2000 (29\% contra $26 \%$ ) y por cuatro puntos en 2003 (23\% contra 19\%), mientras que en los municipios de usos y costumbres el PAN sólo logra ubicarse dos puntos por encima del PRD en 2003.

Lo más interesante son los resultados del PRI en las elec- en los municipios de partidos políticos, en comparación con 2000 (pasa de $42 \%$ a 49\%), cuando en los municipios de usos y costumbres sus resultados siguen bajando (de 53 a 51\%) (véanse cuadros 8 y 9). Es cierto que se trata sólo de $2 \%$ de diferencia, pero es más significativo pues en esas elecciones, a nivel nacional, el PRI obtuvo un repunte espectacular, en detrimento del PAN y el PRD. Además, el PAN gana cuatro puntos en los municipios de usos y costumbres, en comparación con las elecciones de 2000, cuando sufre una caída de seis puntos en los municipios de partidos políticos. Esos resultados confirman la hipótesis de un cambio lento pero constante en las preferencias de los electores que residen en municipios de usos y costumbres. El PRI no deja de perder terreno, elección tras elección, con todo y abstención. La imagen de esos municipios como reserva "natural" del voto prísta queda definitivamente desmentida.

Las elecciones de 2006 corroboran esa tendencia de manera radical. Lo que en 2003 resultó en un carro completo del PRI, como en los viejos tiempos, se volteó totalmente el 2 de julio de 2006: los candidatos de la Coalición
Cuadro 9. Elecciones de diputados federales en los municipios de usos y costumbres

\begin{tabular}{l|c|c|c|c|c}
\hline & 1994 & 1997 & 2000 & 2003 & 2006 \\
\hline PRI & $57 \%$ & $57 \%$ & $53 \%$ & $51 \%$ & $37 \%$ \\
\hline PRD & $27 \%$ & $28 \%$ & $25 \%$ & $20 \%$ & $44 \%$ \\
\hline PAN & $10 \%$ & $8 \%$ & $18 \%$ & $22 \%$ & $16 \%$ \\
\hline Otros & $7 \%$ & $8 \%$ & $4 \%$ & $7 \%$ & $3 \%$ \\
\hline
\end{tabular}

FUENTE: Elaborado por el autor con datos del IEE y del IFE.

por el Bien de Todos, beneficiando del efecto de "arrastre" producido por el voto a favor de Andrés Manuel López Obrador, se llevaron nueve de los once distritos electorales. De la misma manera, la coalición opositora ganó las dos senadurías de mayoría relativa y el PRI se quedó únicamente con la senaduría atribuida a la primera minoría. Se trata, pues, de un verdadero maremoto de la oposición que ha arrasado con los cargos de elección popular a dos años de la elección estatal más competida de la historia moderna de Oaxaca (Ulises Ruiz sólo ganó por poco más de 35000 votos, 3\% de diferencia con Gabino Cué) en una elección fuertemente cuestionada. Esas elecciones confirmaban una evolución de largo alcance y, además, hacían prever elecciones federales adversas al partido que, hasta inicios del tercer milenio, había logrado mantener un control casi absoluto sobre la entidad.

\section{CONCLUSIÓN}

Las movilización magisterial y popular del segundo semestre de 2006 no es un suceso extraordinario. Si bien la violencia política no ha sido tan masiva e intensa desde 1977, lo ocurrido en la ciudad de Oaxaca es reflejo de la descomposición de un régimen político que, ante la ineficacia de los mecanismos tradicionales de clientelización y cooptación, recurre a la fuerza para mantenerse. Elementos del viejo corporativismo - empezando con la sección 22 del SNTE- se encuentran a la deriva; los movimientos "maximalistas" que hasta hoy han vivido de las "concertacesiones" con el gobierno del estado adoptan una estrategia de confrontación porque el gobernador 
Ulises Ruiz ha decidido cumplir los compromisos adquiridos con su "padrino" Roberto Madrazo, en detrimento de todo lo demás. A ese nudo de intereses se le han sumado rencores acumulados entre varios sectores sociales de la ciudad capital (desde los "avecindados" en los márgenes de la ciudad, hartos de esperar las infraestructuras eternamente prometidas, hasta los comerciantes y empresarios que ya no soportaban la corrupción y el nepotismo en la adjudicación de los contratos públicos, pasando por los estudiantes, sin futuro ante el deterioro del sistema educativo). El movimiento acabó siendo algo más que la suma de sus partes. Rebasó a la ciudad capital e involucró a organizaciones y autoridades locales del resto del estado. Aunque la sociedad oaxaqueña se haya polarizado entre los partidarios de la APPO y los de un regreso a la paz, con todo y Ulises Ruiz, el conflicto ha adquirido tanta resonancia porque en todo el estado se venía dando un proceso "hormiga" de cambio político; un proceso casi imperceptible de desmoronamiento del antiguo pacto clientelista que ligaba la autonomía comunal y municipal a la lealtad con el "partido del gobierno" y su jefe en turno. Si bien ese cambio no encontró enseguida una expresión electoral, se ha manifestado en conflictos locales en torno a la definición de las reglas del juego electoral en cada elección municipal, pero también en los altos niveles de abstención (más de 60\% en 2000 y 2003).

Una vez más, las elecciones del 2 de julio de 2006 marcan un parteaguas: por primera vez desde que la información se ha vuelto creíble (desde la creación del IFE a principios de la década de 1990), la abstención apenas ha rebasado $40 \%$. Los resultados expresan un mensaje claro: el rechazo al PRI identificado con un gobernador corrupto y represor, pero también el rechazo al PAN, identificado con un presidente que no pudo o no quiso actuar a tiempo para solucionar el conflicto magisterial en junio de 2006. El del 2 de julio ha sido más un voto de sanción a los responsables políticos, a nivel estatal y federal, que un voto de adhesión a los candidatos de la Coalición por el Bien de Todos y sus propuestas. Es cierto que el discurso anti-establishment de Andrés Manuel López Obrador ha calado hondo entre electores decepcionados de la tan cacareada "alternancia", pero la debilidad estructural del PRD estatal como organización política y el "desen-

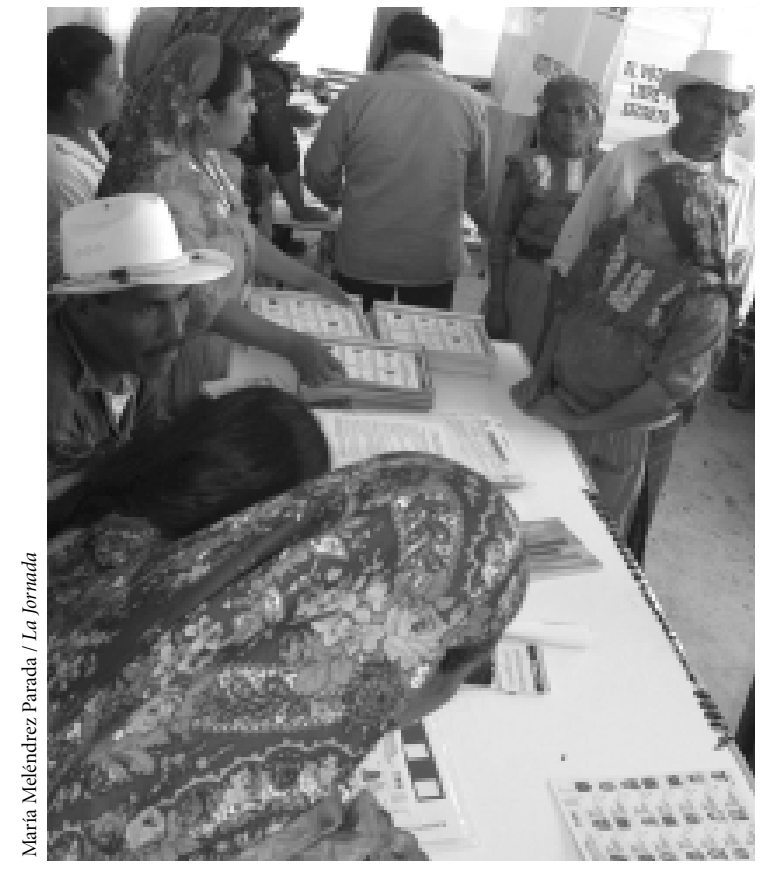

Elecciones federales en San Bartolomé Quialana, Oaxaca, 2 de julio de 2006.

cuentro" entre López Obrador y la APPO hacen pensar que el voto de rechazo favoreció al que menos "compromiso" con la clase gobernante parecía tener (ni el PRI de Roberto Madrazo y Ulises Ruiz, ni el PAN de Vicente Fox, ni el Panal de Elba Esther Gordillo podían asumir seriamente tal ruptura; el Partido Alternativa Socialdemócrata y Campesina tenía muy poca visibilidad y fue descalificado por su trato inicial con Héctor Sánchez López). No obstante, el factor determinante fue la decisión de los maestros "appistas" de suspender el plantón y regresar a las comunidades para llamar a la gente a votar en contra del PRI, del PAN y del Panal. En la mayoría de las regiones, los maestros siguen teniendo una influencia determinante en la vida política local, cuando no son directamente autoridad municipal. Ello explica, en gran parte, la participación electoral sin precedente. Los maestros actuaron como "punteros", movilizando a los electores por todos los medios posibles, incluyendo el muy tradicional “acarreo". La dirigencia magisterial oaxaqueña, en su mayoría anti-partidista y abstencionista, decidió esta vez movilizarse a favor de los candidatos de la Coalición por 
el Bien de Todos como una manera de presionar al gobernador, demostrando su influencia política.

Todo ello, sin embargo, no habría producido resultados tan contundentes si, a la par y durante dos decenios, no se hubiera producido un cambio profundo en las comunidades rurales e indígenas de Oaxaca. Bajo el manto equívoco de los usos y costumbres se esconde una crítica permanente a los mecanismos tradicionales de vinculación entre el poder local y los gobiernos estatales y federales. La costumbre se ha ido zafando de la ganga priísta. En algunas ocasiones eso ha favorecido la consolidación de enclaves autoritarios, a la merced de caciques locales, dispuestos a pactar con el mejor postor. Pero en la mayoría de los casos, no obstante, la renegociación de los usos y costumbres ha favorecido la apertura de espacios de participación y decisión más democráticos (Recondo, 1999: 85-101, 2001b; Velásquez Cepeda, 2005). En un paisaje político tan fragmentado como el de Oaxaca, las articulaciones entre un actor colectivo heterogéneo y poco estructurado como la APPO y las fuerzas políticas regionales y locales son endebles. Pero la formación de una ciudadanía crítica y parcialmente liberada de compromisos clientelares que ya no rinden fruto, probablemente transforme la excepción electoral del 2 de julio de 2006 en una pauta para futuros procesos electorales. En ese contexto, el aparente regreso a la "paz priísta" en Oaxaca suena a canto de cisne.

\section{Bibliografía}

Aguilar, José Antonio y Guillermo Trejo, 2002, "Etnicidad y consolidación democrática. La organización de las elecciones en las regiones indígenas de México", en Aline Hémond y David Recondo (ed.), Dilemas de la democracia en México: los actores sociales ante la representación politica, CEMCA, IFE, México, pp. 195-200.

Anaya Muñoz, Alejandro, 2002, Governability and Legitimacy in Mexico: The Legalisation of Indigenous Electoral Institutions in Oaxaca, tesis doctoral, Universidad de Essex, Inglaterra.

Bartra, Roger, 1999, La sangre y la tinta. Ensayo sobre la condición posmexicana, Océano, México.

De la Peña, Guillermo, 1994, "La ciudadanía étnica y la construcción de los indios en el México contemporáneo", Revista Internacional de Filosofia Politica, núm. 4, noviembre, pp. 116-140.
Díaz Montes, Fausto, 2004, "Elecciones de fin de siglo, Oaxaca (1970-2000)”, en Víctor Raúl Martínez Vásquez (coord.), Oaxaca. Escenarios del nuevo siglo, UABJO, Oaxaca, pp. 241-246.

—_ y Víctor Raúl Martínez Vásquez (coords.), 2001, Elecciones municipales en Oaxaca, IEE, UABJO, Oaxaca.

Flores Cruz, Cipriano, 2005, "Usos y costumbres, un recuento", en Diez voces a diez años. Reflexiones sobre los usos y costumbres a diez años del reconocimiento legal, Educa, Oaxaca, pp. 157-191.

IEE, 1995, Código de instituciones políticas y procedimientos electorales de Oaxaca [CIPPEO].

__ 1998, Compendio de legislación electoral del estado de Oaxaca.

Juan Martínez, Víctor Leonel, 2006a, "Un régimen se muere en Oaxaca”, Marcha, núm. 85, octubre, pp. 11-13.

—_, 2006b, "Oaxaca, la paz ficticia", Marcha, núm. 87, diciembre, pp. 22-25.

_ 2007, "Oaxaca, historia de nota roja”, Marcha, ním. 88, enero-febrero, pp. 14-15.

Kymlicka, Will, 1995, Multicultural Citizenship: a Liberal Theory of Minority Rights, Clarendon Press, Oxford.

Martínez Vásquez, Víctor Raúl, 1990, Movimiento popular y politica en Oaxaca: 1968-1986, Conaculta, México, pp. $159-200$

__ 2004, "Oaxaca: la transición a la democracia”, en Víctor Raúl Martínez Vásquez (coord.), Oaxaca. Escenarios del nuevo siglo, UABJO, Oaxaca, pp. 247-267.

—_, 2007, Autoritarismo, movimiento popular y crisis política en Oaxaca en el 2006, UABJO, Oaxaca.

Recondo, David, 1999, "Usos y costumbres y elecciones en Oaxaca. Los dilemas de la democracia representativa en una sociedad multicultural", TRACE (Travaux et Recherches dans les Amériques du Centre), CEMCA, núm. 36, diciembre, pp. 85-101.

_ 2001a, "Usos y costumbres, procesos electorales y autonomía indígena en Oaxaca”, en Lourdes de León Pasquel (coord.), Costumbres, leyes y movimiento indio en Oaxaca y Chiapas, CIESAS, Porrúa, México, pp. 91-113.

__, 2001b, "Mexique: multiculturalisme et démocratisation dans l'Oaxaca", Problèmes d'Amérique Latine, núm. 41, abril-junio, pp. 45-70.

Velásquez Cepeda, María Cristina, 2000, El nombramiento. Las elecciones por usos y costumbres en Oaxaca, IEE, Oaxaca.

__ 2005, "Lo político de lo electoral en los conflictos municipales de Oaxaca: una reflexión sobre el tránsito de los usos y costumbres al sistema de partidos políticos", en Diez voces a diez años. Reflexiones sobre los usos y costumbres a diez años del reconocimiento legal, Educa, Oaxaca, pp 107-125. 